\title{
Uso do Sensoriamento Remoto Orbital no Monitoramento da Dispersão de Macrófitas nos Reservatórios do CompleXo TIETÉ ${ }^{1}$
}

\author{
Remote Satellite Sensing to Monitor Macrophyte Dispersion in the Tietê River Reservoirs
}

GALO, M.L.B.T. ${ }^{2}$, VELINI, E.D. ${ }^{3}$, TRINDADE, M.L.B. ${ }^{4}$ e SANTOS, S.C.A. ${ }^{5}$

\begin{abstract}
RESUMO - A presença de algumas substâncias na água, como pigmentos fotossintetizantes, particulados, etc., afeta sua cor, provocando mudanças na radiância da água registrada por sensores orbitais. Nesse sentido, o sensoriamento remoto pode se constituir em uma fonte complementar de dados para o monitoramento da qualidade da água em grandes reservatórios (Novo et al., 1994). No contexto de um projeto de pesquisa realizado na AES Tietê S.A., com o objetivo de desenvolver técnicas para a avaliação da área com infestação de plantas aquáticas, imagens orbitais multiespectrais foram usadas tanto para mapear a dispersão espacial e estimar a área de ocorrência de macrófitas aquáticas, em duas épocas distintas, quanto para orientar a definição de pontos de amostragem in loco, visando a coleta e posterior análise da água e de sedimentos nos reservatórios. Este trabalho apresenta uma descrição do procedimento metodológico adotado na análise das imagens multiespectrais, bem como os resultados obtidos na caracterização dos reservatórios de Barra Bonita, Bariri, Ibitinga, Promissão e Nova Avanhandava, em termos de seu dimensionamento, variabilidade espectral da água e presença de macrófitas emersas, nas duas épocas do ano consideradas.
\end{abstract}

Palavras-chave: sensoriamento remoto, resposta espectral da água, mapeamento da dispersão espacial de macrófitas.

\begin{abstract}
Water color is affected by substances that change the water radiance detected by satellite sensors. Thus, remote sensing techniques may be used as a complementary data source to monitor water quality in large reservoirs (Novo et al., 1994). Within the context of a research project, whose main purpose is to develop techniques to evaluate macrophyte infestation levels in AES Tietê reservoirs, multi spectral satellite images were used to: a) map microphyte spatial dispersion and evaluate their area of occurrence, in two periods and, b) locate points to collect water samples. This paper presents the methodology adopted and the results obtained from Barra Bonita, Bariri, Ibitinga, Promissão and Nova Avanhandava reservoir analyses, concerning their size, water body spectral variability and macrophyte infestation area during two periods (wet and dry seasons).
\end{abstract}

Key words: remote sensing, water spectral response, mapping of macrophyte dispersion.

\section{INTRODUÇÃO}

Os reservatórios caracterizam-se por apresentar um gradiente espacial na carga de sedimentos e nutrientes ao longo de seu corpo, o que, aliado ao tamanho dos reservatórios brasileiros, torna o monitoramento das propriedades da água extremamente caro e demorado. Nesse sentido, o sensoriamento remoto pode se constituir em uma fonte complementar de dados para o monitoramento da qualidade da água em grandes reservatórios (Novo et al., 1989).

Recebido para publicação em 12/11/2001 e na forma revisada 5/1/2002.

2 Departamento de Cartografia, FCT-UNESP, Campus de Presidente Prudente. ${ }^{3}$ Departamento de Agricultura, FCA-UNESP, Campus de Botucatu. ${ }^{4}$ Criativa - Consultoria em Matologia e Meio Ambiente S/C Ltda. ${ }^{5}$ AES Tietê S.A. 
O sensoriamento remoto da água se baseia no fato de que os componentes nela presentes afetam a sua cor, cujas mudanças são decorrentes de alterações na radiância da água, e essa variação pode ser registrada por sensores orbitais (Novo et al., 1989). Considerando que as características dos sensores remotos orbitais quanto à sua resolução espacial e espectral e os mecanismos de interação da radiação eletromagnética com a água definem uma variabilidade espectral bastante tênue para os corpos d'água, a maioria dos estudos sobre qualidade da água, utilizando o sensoriamento remoto, tem se limitado à detecção de particulados em suspensão e de vegetação aquática emersa.

Assim, se por um lado existe uma limitação técnica dos dados multiespectrais adquiridos sistematicamente a partir de plataformas orbitais para aplicações com água, a dimensão do espelho d'água de muitos reservatórios brasileiros pode inviabilizar programas de monitoramento da qualidade da água, em face do alto custo da implementação de um esquema de amostragem adequado. Devido ao seu caráter sinóptico e repetitivo, as imagens de satélite podem se constituir em um recurso auxiliar valioso no processo de alocar adequadamente pontos de amostragem no reservatório e mesmo de mapear a distribuição espacial de alguns componentes presentes no corpo d’água.

Considerando o exposto, vem sendo desenvolvido um projeto de pesquisa na AES Tietê S.A., cujo objetivo é desenvolver técnicas para a avaliação da área com infestação de plantas aquáticas. Para esse projeto foi proposta a utilização de imagens orbitais de sensoriamento remoto tanto para verificar a ocorrência de macrófitas aquáticas, em duas épocas distintas, quanto para orientar a definição de pontos de amostragem in loco, visando a coleta e posterior análise da água e de sedimentos nos reservatórios.

No contexto da análise da dispersão de macrófitas aquáticas nos reservatórios que integram o complexo Tietê, gerenciados pela AES Tietê S.A., as imagens de sensoriamento remoto foram utilizadas na caracterização dos reservatórios de Barra Bonita, Bariri, Ibitinga, Promissão e Nova Avanhandava, em termos de seu dimensionamento e da variabilidade espectral da água em duas épocas do ano distintas: a primeira a partir de dados tomados entre fevereiro e março de 2001 e a segunda entre junho e agosto de 2001. Esses dados orbitais constituídos pelas imagens ETM+/Landsat foram usados, ainda, para alocar pontos de amostragem ao longo dos reservatórios, nos quais vêm sendo coletados dados in loco.

Assim, o objetivo do presente trabalho é descrever as atividades desenvolvidas mediante a utilização de dados e técnicas de sensoriamento remoto, assim como discutir algumas estimativas realizadas no âmbito do projeto de pesquisa. Especificamente, é apresentada a abordagem metodológica adotada no processamento e na análise das imagens de satélite, além de alguns resultados explicitados na forma de mapas temáticos, tabelas destacando as estimativas da área de cada reservatório e a área de abrangência de macrófitas, nas duas épocas consideradas.

A seguir estão descritos alguns fundamentos teóricos da aplicação do sensoriamento remoto em estudos da água, de caráter imprescindivel para o entendimento da abordagem concebida.

\section{Sensoriamento remoto orbital}

Ao interagir com a superficie terrestre, a radiação eletromagnética pode sofrer absorção, reflexão e transmissão, dependendo das propriedades desta superfície e do intervalo espectral considerado. Os comprimentos de onda nos quais a radiação é refletida e transmitida são utilizados na identificação dos alvos em sensoriamento remoto.

Os sistemas de aquisição de dados de sensoriamento remoto, definidos como sistemas sensores, constituem-se de qualquer equipamento capaz de transformar a radiação eletromagnética refletida pelos alvos da superfície terrestre em um sinal passivel de ser convertido em informações sobre o meio ambiente (Novo, 1989). Dentre a grande variedade de equipamentos que apresentam essa capacidade, podem ser destacados os sensores imageadores, os quais fornecem como produto uma imagem da cena observada.

Conforme descreve Novo (1989), os diferentes sistemas sensores são caracterizados pela sua resolução, definida como uma medida 
da habilidade que o sensor possui de distinguir entre respostas espectralmente semelhantes e espacialmente próximas. Além da resolução espacial que mede a menor separação linear ou angular entre dois objetos da superfície terrestre, os sistemas de varredura instalados em satélites podem ser caracterizados em termos de sua resolução espectral, que é uma medida da largura das faixas espectrais nas quais o sensor opera; resolução radiométrica, relacionada com a sensibilidade do sensor em distinguir entre dois níveis de intensidade do sinal de retorno; e resolução temporal, relativa ao intervalo de tempo entre a aquisição de duas imagens de uma mesma área.

A aquisição de dados de sensoriamento remoto, com aplicação em recursos naturais, pode ser feita por meio de sensores instalados em plataformas orbitais. Dentre os sistemas sensores atualmente em operação, podem ser destacados o TM - Thematic Mapper (instalado a bordo dos satélites Landsat 4 e 5); e os sensores HRV - Haute Resolution Visible, os quais constituem a carga útil do satélite francês SPOT. Em 1999 foi lançado com sucesso um novo satélite americano - o Landsat 7 - cujo sensor ETM+ (Enhanced Thematic Mapper Plus) tem características técnicas que são um aprimoramento do TM.

Operando a bordo do satélite Landsat 5, o Thematic Mapper - TM constitui-se de um sensor imageador óptico multiespectral que coleta dados da superfície terrestre, simultaneamente, em sete bandas espectrais. Seis dessas bandas operam na região refletida do espectro óptico e apresentam uma resolução espacial de 30 metros no terreno. A outra banda espectral, designada como banda TM6, capta a radiação termal e tem uma resolução espacial de 120 metros. Na Tabela 1 são apresentadas as principais bandas espectrais do sensor TM, assim como os intervalos de comprimento de onda que as definem e suas principais aplicações.

Em comparação com o TM, o sensor ETM+ mantém a designação e as resoluções espacial (30 metros) e espectral ( 6 bandas no espectro refletivo). As exceções ficam por conta da banda termal, que, apesar de continuar sendo a de número 6, teve sua resolução espacial melhorada (60 metros), e da incorporação de uma banda pancromática (definida no intervalo espectral entre 0,52 e 0,90 $\mu \mathrm{m}$ ), com resolução de 15 metros (Sheffner, 1999).

Tabela 1 - Principais aplicações das bandas espectrais do sensor TM/Landsat

\begin{tabular}{|c|c|c|}
\hline Bandas espectrais & Intervalo espectral $(\mu \mathrm{M})$ & Principais aplicações \\
\hline \multirow{2}{*}{ TM1 } & $0,45-0,52$ & $\begin{array}{l}\text { - Mapeamento de águas costeiras } \\
\text { - Diferenciação entre solo e vegetação } \\
\text { - Diferenciação entre coníferas e folhosas }\end{array}$ \\
\hline TM2 & $0,52-0,60$ & - Reflectância da vegetação verde sadia \\
\hline TM3 & $0,63-0,69$ & $\begin{array}{l}\text { - Absorção pela clorofila } \\
\text { - Diferenciação entre espécies vegetais }\end{array}$ \\
\hline TM4 & $0,76-0,90$ & $\begin{array}{l}\text { - Levantamento de biomassa vegetal } \\
\text { - Delineamento de corpos d'água }\end{array}$ \\
\hline TM5 & $1,55-1,75$ & $\begin{array}{l}\text { - Medidas de umidade da vegetação } \\
\text { - Diferenciação entre nuvens e neve }\end{array}$ \\
\hline TM6 & $10,4-12,5$ & $\begin{array}{l}\text { - Mapeamento de estresse térmico em plantas } \\
\text { - Outros mapeamentos térmicos }\end{array}$ \\
\hline TM7 & $2,08-2,35$ & \begin{tabular}{l} 
- Mapeamento hidrotermal \\
\hline
\end{tabular}
\end{tabular}

Fonte: Novo (1989). 
Em setembro de 1999, com o sucesso do lançamento do satélite IKONOS II, a comunidade de sensoriamento remoto passou a dispor das imagens de alta resolução geradas a partir dessa plataforma. Os dados orbitais do IKONOS são disponibilizados em dois modos de aquisição: pancromático e multiespectral. Os dados pancromáticos apresentam resolução espacial de 1 metro no terreno e abrangência espectral de 0,45 a $0,90 \mu \mathrm{m}$. As imagens multiespectrais têm resolução espacial de 4 metros e são obtidas em 4 bandas espectrais correspondentes aos intervalos de comprimento de onda entre 0,45 e 0,52 $\mu \mathrm{m}$ (azul), 0,52 e $0,60 \mu \mathrm{m}$ (verde), 0,63 e $0,69 \mu \mathrm{m}$ (vermelho) e 0,76 e $0,90 \mu \mathrm{m}$ (infravermelho próximo). Independentemente do modo de aquisição, a resolução radiométrica é de 11 bits (2.048 níveis de cinza), proporcionando maior poder de contraste e discriminação para as imagens produzidas (INTERSAT, 2001).

\section{Interação da radiação eletromagnética com a água}

No contexto do sensoriamento remoto, a reflectância espectral, caracterizada dentro de um intervalo de comprimento de onda e segundo uma determinada geometria de aquisição, define o comportamento espectral de um alvo, sendo essa definição amplamente utilizada, em sensoriamento remoto, para a caracterização dos alvos.

Diferente do solo e da vegetação, a maior parte do fluxo radiante incidente sobre a água não é refletida, mas absorvida ou transmitida. Nos comprimentos de onda do visível, pouca luz é absorvida, uma pequena quantidade é refletida e a maior parte é transmitida. Moreira (2001) destaca que a água no estado líquido absorve toda a radiação eletromagnética abaixo de $380 \mathrm{~nm}$ e acima de $700 \mathrm{~nm}$ e que, mesmo nessa faixa intermediária, a reflectância da água é relativamente pequena, ultrapassando pouco mais de 5\%. Especificamente para a água pura, a reflectância no espectro visível decresce de cerca de $5 \%$ no azul para menos de $1 \%$ no infravermelho próximo (Novo et al., 1989). Desse modo, a forte absorção da radiação do infravermelho próximo e médio pela água resulta em um forte contraste entre a água e os limites de terra.
Segundo Robin (1995), a água pura tem uma resposta espectral característica: sua reflectância é elevada no intervalo espectral correspondente à luz azul, diminui no verde, é fraca no vermelho e quase nula no infravermelho próximo. Na realidade, a água absorve inteiramente a radiação do infravermelho próximo incidente já nos primeiros milímetros da coluna d'água.

\section{Fatores que interferem na reflectância da água}

Segundo Curran (1985), os fatores que afetam a variabilidade espectral na reflectância de um corpo d'água são, geralmente, determinados pelo ambiente. Os três fatores mais importantes são: profundidade do corpo d'água, presença de materiais em suspensão e rugosidade da superfície do corpo d'água.

Novo et al. (1994) argumentam que os componentes da água absorvem seletivamente a luz que chega ao volume d'água, sendo essa absorção máxima em alguns comprimentos de onda. Os pigmentos fotossinteticamente ativos são responsáveis pela absorção nas regiões espectrais do azul e do vermelho, de modo que um aumento na quantidade de fitoplâncton na água produz redução na quantidade dessa energia e a cor da água é percebida como verde. A matéria orgânica dissolvida é também responsável por mudança no coeficiente de absorção da água, ocorrendo um máximo na região do azul e decrescendo com o comprimento de onda. Como conseqüência, a cor da água muda do azul (água limpa) e verde (água rica em fitoplâncton) para o amarelo, conforme o aumento da quantidade dos componentes orgânicos dissolvidos.

Algumas das observações anteriores são reafirmadas por Robin (1995) com base em resultados de simulações realizadas para analisar o efeito da concentração de clorofila, particulados e matéria orgânica dissolvida sobre a reflectância do mar. O autor relata que:

- um aumento na concentração de clorofila (fitoplâncton) se traduz por diminuição da reflectância no azul e no vermelho, aumento no infravermelho próximo e manutenção da reflectância no verde;

- quando a água tem alta carga de turbidez mineral (partículas não-clorofiladas), sua 
refelectância aumenta e tende a se aproximar daquela do solo, em decorrência do aumento da reflexão no verde, vermelho e infravermelho próximo;

- quando a água carreia materiais orgânicos dissolvidos (aumento na concentração de substâncias amarelas), sua reflectância diminui como a de um solo rico em matéria orgânica.

No que se refere à mudança na resposta espectral em decorrência da presença de materiais inorgânicos na água, Novo et al. (1989) analisaram sedimentos com coloração e granulometria diferentes e concluíram que o tipo do particulado pode afetar o grau de correlação entre a concentração dos sedimentos em suspensão e a reflectância e que esse efeito é mais perceptivel nos menores comprimentos de onda.

Tentativas de correlacionar a resposta espectral com a ocorrência de componentes que indiquem a qualidade da água em grandes reservatórios têm sido relatadas desde que as imagens orbitais MSS/Landsat tornaram-se disponiveis (Ritchie et al., 1976; Scarpace et al., 1979). Com a disponibilidade das imagens TM, foram realizados experimentos para verificar se o aumento na resolução espacial dessas imagens permitiria estimativas da concentração dos componentes individuais da água. No entanto, conforme salienta Novo et al. (1994), a maior limitação desses dados é sua resolução espectral inadequada para estudos da água, a qual não permite discriminar componentes opticamente ativos, principalmente quando ocorrem simultaneamente altas concentrações de clorofila e material inorgânico.”

Por outro lado, os mesmos autores destacam que, embora o sensor TM não tenha sido projetado para estudos da água, os dados obtidos podem fornecer informações consistentes sobre a presença de matéria inorgânica e as condições ópticas do meio aquático.

\section{MATERIAL E MÉTODO}

Considerando os aspectos relacionados com a utilização de dados de sensoriamento remoto, inicialmente voltados à identificação de pontos de amostragem para coleta de água e especificamente direcionados para o monitoramento da distribuição espacial de macrófitas emersas nos reservatórios de Barra Bonita, Bariri, Ibitinga, Promissão e Nova Avanhandava, apresenta-se o desenvolvimento metodológico adotado nessa fase do projeto levando em conta as variações espectrais da água nos referidos reservatórios em duas épocas distintas (estações seca e chuvosa). Nesse desenvolvimento estão incluídos: a caracterização dos reservatórios e das imagens de satélite utilizadas; a especificação dos aplicativos computacionais usados no processamento dos dados espaciais; e o procedimento concebido para a análise dos dados multiespectrais.

\section{Caracterização dos reservatórios e dados multiespectrais utilizados}

Para facilitar a definição das imagens ETM+/Landsat necessárias à análise individual de cada reservatório de interesse (Barra Bonita, Bariri, Ibitinga, Promissão, Nova Avanhandava), foram levantadas algumas informações referentes tanto à localização e às referências geográficas dos reservatórios quanto à sua área de abrangência.

Em seguida, usando um mapa de referência das órbitas/ponto que definem as imagens TM e ETM+/Landsat, foram selecionadas as cenas que compõem a área de abrangência dos reservatórios da AES Tietê S.A., a partir da identificação das órbitas/ponto das imagens de interesse. Posteriormente, foi solicitado à Intersat, uma das empresas que comercializam imagens de satélite no Brasil, a disponibilização de quick looks (imagens reamostradas com baixíssima resolução espacial) das cenas correspondentes às órbitas/ponto selecionadas por meio do mapa de referência. Através desses quick looks foram efetivamente determinadas as imagens ETM+/Landsat que foram avaliadas no decorrer do projeto.

Na Tabela 2 são apresentadas as principais características dos reservatórios em questão, assim como as órbitas/ponto das imagens e respectivas datas de passagem das cenas ETM+/Landsat analisadas.

Cada uma das cenas, definidas pelas suas respectivas órbitas/ponto, abrange uma área na superfície terrestre de $183 \times 183 \mathrm{~km}$, e, como pode ser verificado na Tabela 2 , para representação integral do reservatório de Nova Avanhandava, são necessárias duas órbitas/ 
ponto. Cada imagem ETM+/Landsat adquirida incluiu todas as bandas do espectro refletivo (com resolução espacial de 30 metros) e a banda pancromática (resolução espacial de 15 metros). Essas imagens foram obtidas em formato GEOTIFF, a fim de se dispor de dados previamente georreferenciados para os reservatórios.

\section{Aplicativos computacionais usados na análise dos dados de sensoriamento remoto}

No desenvolvimento do projeto foram utilizados dois aplicativos, os quais forneceram as ferramentas necessárias para a análise dos dados de sensoriamento remoto: o Spring e o Idrisi. Embora ambos se constituam em Sistemas de Informações Geográficas, esses softwares apresentam funções diferenciadas que os tornam aplicáveis a situações distintas.

O Spring é um aplicativo de domínio público desenvolvido pelo INPE (Instituto Nacional de Pesquisas Espaciais) que incorpora a funcionalidade de bancos de dados no gerenciamento dos dados, além de recursos específicos para processamento e análise de dados multiespectrais.

O Idrisi, desenvolvido pela Clark University, é um aplicativo que permite a análise de dados em formato matricial, sendo especialmente adequado para o desenvolvimento de análises estatísticas e voltadas para o meio ambiente.

\section{Procedimento adotado no tratamento e na análise dos dados multiespectrais}

As atividades relacionadas com o processamento e a análise dos dados de sensoriamento remoto foram desenvolvidas de maneira similar para cada data de aquisição de dados e constaram de:

\section{- Criação de bancos de dados e projetos no Spring}

Considerando que um Banco de Dados no Spring é a entidade que gerencia um ou mais Projetos, os quais são definidos pela abrangência geográfica da área de interesse, partiu-se do princípio de que cada reservatório deveria constituir um único Projeto. Além disso, para manter o georreferenciamento da imagem original, foi necessário definir projetos abrangendo inicialmente toda a cena. Nesse sentido, foram criados dois Bancos de Dados, o primeiro para gerenciar a área correspondente ao reservatório de Barra Bonita e um segundo para os demais reservatórios, definidos pelos Projetos Bariri, Ibitinga, Promissão e Nova Avanhandava.

A função Mosaico do Spring permite a cópia das imagens (caracterizadas como Planos de Informação - PIs) entre Projetos diferentes (com área geográfica menor), de um mesmo Banco de Dados, sem perder os parâmetros de georreferenciamento. Essa função foi usada para gerar os PIs correspondentes aos reservatórios,

Tabela 2 - Características dos reservatórios e das imagens ETM+/Landsat utilizadas

\begin{tabular}{|c|c|c|c|c|}
\hline Reservatório & Área (ha) & Tipo de reservatório & $\begin{array}{c}\text { Órbita/ponto cena } \\
\text { ETM+ }\end{array}$ & Data de tomada da imagem \\
\hline Barra Bonita & 32.900 & Acumulação & $220 / 76$ & $\begin{array}{l}\text { 23/março/2001 } \\
27 / \text { junho/2001* }\end{array}$ \\
\hline Bariri & 5.500 & Filme líquido & $221 / 75$ & $\begin{array}{l}\text { 26/fevereiro/2001 } \\
\text { 20/julho/2001* }\end{array}$ \\
\hline Ibitinga & 12.350 & Acumulação & $221 / 75$ & $\begin{array}{l}\text { 26/fevereiro/2001 } \\
\text { 20/julho/2001* }\end{array}$ \\
\hline Promissão & 60.500 & Acumulação & $221 / 75$ & $\begin{array}{l}\text { 26/fevereiro/2001 } \\
\text { 20/julho/2001* }\end{array}$ \\
\hline Nova Avanhandava & 21.270 & Filme líquido & $\begin{array}{l}221 / 75 \\
222 / 75\end{array}$ & $\begin{array}{l}\text { 26/fevereiro/2001 } \\
\text { 20/julho/2001* } \\
\text { 05/março/2001 } \\
\text { 20/agosto/2001* }\end{array}$ \\
\hline
\end{tabular}

* Data de tomada de dados correspondente à segunda fase da análise (época mais seca). 
copiando-os para os Projetos de área geográfica menor (área de interesse).

Uma diferença em relação a esse procedimento-padrão decorreu da necessidade de se fazer uma junção lateral de duas órbitas/ponto quando um reservatório específico não estava integralmente definido em uma única cena (o que ocorreu com Nova Avanhandava). Nesse caso, foi necessário criar Projetos individualizados para cada órbita/ponto (gerenciados por um único Banco de Dados), pesquisar no histograma de freqüências o valor de brilho médio, em cada uma das bandas espectrais na região de sobreposição entre as duas órbitas/ponto, e equalizar as médias em cada uma das bandas espectrais. Feito isso, as duas imagens puderam ser compostas para formar um único Projeto, abrangendo toda a extensão do reservatório.

Realizados os procedimentos necessários à criação dos Bancos de Dados, à definição do retângulo envolvente dos Projetos e à especificação dos Modelos de Dados associados às categorias Imagem e Temático, pôde-se iniciar efetivamente o processo de definição do contorno de cada reservatório, a fim de que as variações espectrais dentro do corpo d'água pudessem ser melhor discriminadas.

\section{- Segmentação da imagem}

Normalmente, o processo de separar as áreas de água das de terra em uma imagem multiespectral é operacionalmente simples, bastando definir e aplicar um limiar a uma banda espectral do infravermelho próximo. No entanto, uma análise preliminar das imagens indicou uma resposta espectral bastante diferenciada para a água e as áreas infestadas por macrófitas aquáticas, o que inviabilizou a limiarização. Como essas áreas infestadas devem estar representadas na classificação final, buscou-se uma alternativa que as incluísse no contorno dos reservatórios.

A solução encontrada foi substituir a limiarização pela segmentação e classificação por regiões, de modo a incluir a água e as áreas infestadas na área de influência do reservatório. O método de segmentação adotado foi o de crescimento de regiões, que consiste no agrupamento de conjuntos de pixels (regiões) espacialmente adjacentes e que é desenvolvido com base em um critério de similaridade espectral que verifica se a média entre duas regiões contíguas está consistente com um limiar preestabelecido. O resultado da aplicação desse algoritmo é uma imagem dividida em regiões independentes, cada qual caracterizada por uma identificação que a representa.

Assim, para cada reservatório/Projeto do Spring foi feita uma segmentação da imagem pelo método crescimento de regiões. Para isso, foram utilizados: as bandas espectrais ETM+1, $\mathrm{ETM}+2, \mathrm{ETM}+3, \mathrm{ETM}+4, \mathrm{ETM}+5$ e $\mathrm{ETM}+7$, um valor de similaridade (distância euclidiana máxima admissivel entre as médias de um par de regiões adjacentes) igual a 8 ou 12 e um limiar de agregação (número mínimo de pixels necessário para configurar uma região) de 15 ou 20. Os diferentes valores estabelecidos para esses dois últimos parâmetros dependeram da dimensão do retângulo envolvente do Projeto definido para cada reservatório, isto é, reservatórios que se estendem por grandes áreas definem imagens muito grandes, onerando consideravelmente o tempo computacional para essa operação.

Em suma, para os grandes reservatórios adotou-se similaridade igual a 12 e agregação de 20, enquanto para os pequenos reservatórios esses valores foram de 8 e 15, respectivamente.

\section{- Classificação da imagem segmentada}

A classificação supervisionada das regiões definidas na segmentação foi feita a partir da definição prévia e da aquisição de amostras para classes de treinamento referentes a duas variações espectralmente perceptíveis de água e a macrófitas. A partir da definição das amostras de treinamento e extração dos parâmetros estatísticos que representam cada classe, foi aplicado um algoritmo de classificação, o qual se baseia na menor distância de Bhattacharya calculada entre cada classe e cada região definida na imagem segmentada e um limiar de aceitação predefinido (nível de significância para cada classe, que confere maior ou menor rigidez ao classificador, quando da atribuição das regiões às classes).

Com a aplicação desse procedimento, na imagem classificada resultante ficaram representadas apenas as regiões atribuídas às classes designadas como água 1 , água 2 ou 
macrófitas, porém algumas dessas regiões constituíram áreas isoladas, não contíguas ao espelho d'água que define o reservatório, sendo necessário editar a cena classificada.

\section{- Edição da classificação}

Para editar uma classificação é preciso que a imagem esteja definida no modelo temático e que as classes constituam temas. Essa operação é definida como mapeamento das classes e consiste em associar as classes (águas 1 e 2 e macega) a temas correspondentes nessa outra categoria de dados. A edição propriamente dita consiste em remover as áreas classificadas águas ou macega que estejam situadas fora da área determinada pelo espelho d'água do reservatório, associando-as a nenhuma das classes de interesse.

\section{- Processamentos efetuados no Idrisi}

Apesar de todos os processamentos que definiram as classificações da área de abrangência de cada reservatório terem sido desenvolvidos no aplicativo Spring, para gerar os mapas temáticos abrangendo todos os reservatórios (um para cada data de tomada das imagens), optou-se por fazer a junção dessas classificações usando o software Idrisi, a partir do qual foram produzidos os mapas temáticos apresentados nos resultados.

\section{RESULTADOS E DISCUSSÃO}

As características dos Projetos constituídos para representar cada reservatório no Spring estão sumariadas na Tabela 3. Nesta tabela explicita-se a denominação adotada para os Bancos de Dados e Projetos criados, o sistema de projeção e Datum adotados e as coordenadas planas no sistema UTM que definem a área retangular delimitada para cada Projeto, associados às respectivas épocas de tomada de dados.

Para ilustrar a configuração dos Projetos caracterizados na Tabela 3, em termos de sua representação espacial e espectral em uma imagem multiespectral, foi adotado o reservatório de Barra Bonita como exemplo e elaboradas composições coloridas das bandas ETM+3,

Tabela 3 - Características dos Projetos constituídos para representar cada reservatório

\begin{tabular}{|c|c|c|c|c|c|}
\hline \multicolumn{2}{|c|}{ Reservatório } & Banco de Dados & Projeto & $\begin{array}{c}\text { Sistema de } \\
\text { Projeção/Datum }\end{array}$ & Coordenadas UTM \\
\hline \multirow{2}{*}{ Barra Bonita } & Fase I & B_Bonita1 & BBonita_1 & UTM/SAD 69 & $\begin{array}{l}E_{1}=737000 \text { a } E_{2}=820000 \\
N_{1}=7463000 \text { a } N_{2}=7521000\end{array}$ \\
\hline & Fase II & B_Bonita2 & BBonita_2 & UTM/WGS 84 & $\begin{array}{l}E_{1}=738000 \text { a } E_{2}=819000 \\
N_{1}=7463400 \text { a } N_{2}=7520700\end{array}$ \\
\hline \multirow{2}{*}{ Bariri } & Fase I & Rio_Tietê1 & Bariri_1 & UTM/SAD 69 & $\begin{array}{l}E_{1}=706520 \text { a } E_{2}=749600 \\
N_{1}=7505360 \text { a } N_{2}=7550000\end{array}$ \\
\hline & Fase II & Rio_Tietê2 & Bariri_2 & UTM/WGS 84 & $\begin{array}{l}E_{1}=706470 \text { a } E_{2}=749550 \\
N_{1}=7505361 \text { a } N_{2}=7549956\end{array}$ \\
\hline \multirow{2}{*}{ Ibitinga } & Fase I & Rio_Tietê1 & Ibitinga_1 & UTM/SAD 69 & $\begin{array}{l}E_{1}=688000 \text { a } E_{2}=758500 \\
N_{1}=7546500 \text { a N } N_{2}=7597500\end{array}$ \\
\hline & Fase II & Rio_Tietê2 & Ibitinga_2 & UTM/WGS 84 & $\begin{array}{l}E_{1}=687950 \text { a } E_{2}=758751 \\
N_{1}=7546456 \text { a } N_{2}=7597456\end{array}$ \\
\hline \multirow{2}{*}{ Promissão } & Fase I & Rio_Tietê1 & Promissão_1 & UTM/SAD 69 & $\begin{array}{l}E_{1}=621650 \text { a } E_{2}=708500 \\
N_{1}=7556300 \text { a } N_{2}=7671950\end{array}$ \\
\hline & Fase II & Rio_Tietê2 & Promissão_2 & UTM/WGS 84 & $\begin{array}{l}E_{1}=621600 \text { a } E_{2}=708450 \\
N_{1}=7555956 \text { a } N_{2}=7671906\end{array}$ \\
\hline \multirow{2}{*}{ Nova Avanhandava } & Fase I & Rio_Tietê1 & NAvanh_1 & UTM/SAD 69 & $\begin{array}{l}E_{1}=576020 \text { a } E_{2}=628010 \\
N_{1}=7624000 \text { a N } N_{2}=7681980\end{array}$ \\
\hline & Fase II & Rio_Tietê2 & NAvanh_2 & UTM/WGS 84 & $\begin{array}{l}E_{1}=575970 \text { a } E_{2}=627970 \\
N_{1}=7623956 \text { a N } N_{2}=7681936\end{array}$ \\
\hline
\end{tabular}


$\mathrm{ETM}+4$ e ETM+5, associadas respectivamente às componentes de cor azul $(B)$, verde $(G)$ e vermelho (R), as quais são mostradas na Figura 1-a (referente aos dados obtidos em março de 2001) e b (cena tomada em junho de 2001).

Comparando a cor da água do corpo do reservatório nas imagens de março e junho, percebe-se claramente maior variação na resposta espectral da água na cena de março de 2001 (Figura 1-a), o que não é tão perceptível na imagem de junho (Figura 1-b). As variações de tonalidade azul, diferente do preto predominante no corpo do reservatório (que é decorrente da total absorção dos comprimentos de onda da radiação do infravermelho próximo pela água limpa), devem-se à presença de sedimentos em suspensão no corpo d'água, o que é detectado na banda ETM+3, cujos níveis de resposta espectral foram associados à componente de cor azul.

Apesar de a escala de representação das composições coloridas mostradas na Figura 1 não possibilitar uma delimitação perfeitamente nítida da área de infestação de macrófitas emersas, esse tipo de fenômeno aparece em um tom de verde intenso no corpo do reservatório, principalmente nos braços dos rios Piracicaba e Tietê. Uma melhor definição da ocorrência de macrófitas é percebida na Figura 2, por meio das imagens resultantes da classificação do reservatório de Barra Bonita, a partir dos dados tomados em março (a) e junho (b) de 2001.

Além de permitir facilitar a percepção da presença de macrófitas no reservatório de Barra Bonita, indicando nitidamente que em março de 2001 (Figura 2-a) esse tipo de fenômeno ocorria de modo disperso ao longo do corpo d'água, ao contrário de junho de 2001 (Figura 2-b), em que as áreas de infestação por macrófitas estão concentradas nos braços dos principais tributários do reservatório, as classificações obtidas mostram a definição clara dos dois tipos de água percebidos na Figura 1. Como especificado anteriormente, esses diferentes tipos de água estão relacionados com a maior ou menor concentração de sedimentos em suspensão, ou seja, à turbidez da água, o que é particularmente representativo na cena tomada em março de 2001 (Figura 2-a).
As cenas classificadas possibilitam tanto a visualização e análise da distribuição espacial dos fenômenos registrados nas imagens multiespectrais, como também permitem obter estimativas da área ocupada pelas classes de interesse. Desse modo, a fim de indicar a dispersão das áreas infestadas por macrófitas, e uma eventual variação na cor da água associada à ocorrência de sedimentos em suspensão, são apresentadas nas Figuras 3, 4, 5 e 6 as classificações obtidas para os reservatórios de Bariri, Ibitinga, Promissão e Nova Avanhandava, respectivamente, em cada uma das duas épocas de tomada de dados multiespectrais (a e b).

Para o reservatório de Bariri (Figura 3) percebe-se uma situação contrária à que foi observada em Barra Bonita (Figura 2) quanto à dispersão de macrófitas ao longo do reservatório. Enquanto em Barra Bonita a maior dispersão ocorria na época mais chuvosa (março/ 2001), em Bariri a dispersão de macrófitas, definindo regiões de concentração de plantas ao longo do corpo d'água, ocorre agora na cena tomada na época mais seca. Ou seja, esse fenômeno foi consideravelmente mais representativo na imagem de julho/2001 (Figura 3-b) em comparação com a imagem de fevereiro/ 2001 (Figura 3-a). No mais, a Figura 3 indica que quase não houve variabilidade espectral na água decorrente da presença de sedimentos em suspensão.

Tendência similar àquela verificada na Figura 3 para Bariri pode ser observada para o reservatório de Ibitinga (Figura 4), onde a maior dispersão de macrófitas foi mapeada a partir da imagem tomada em julho/2001 (Figura 4-b). No reservatório de Ibitinga, a variação na resposta espectral da água é percebida nos rios tributários, com pequeno incremento em julho/2001 (Figura 4-b) em relação a fevereiro/2001 (Figura 4-a).

Quanto ao reservatório de Promissão, cuja classificação obtida é mostrada na Figura 5, percebe-se novamente a dispersão de bancos de macrófitas no corpo do reservatório na época mais seca (Figura 5-b). A classificação obtida para a imagem tomada em fevereiro/2001 (Figura 5-a) sugere maior homogeneidade da água nessa época, quando comparada com aquela obtida a partir dos dados de julho/2001, a qual apresenta alguns braços com água com alguma variabilidade espectral. 


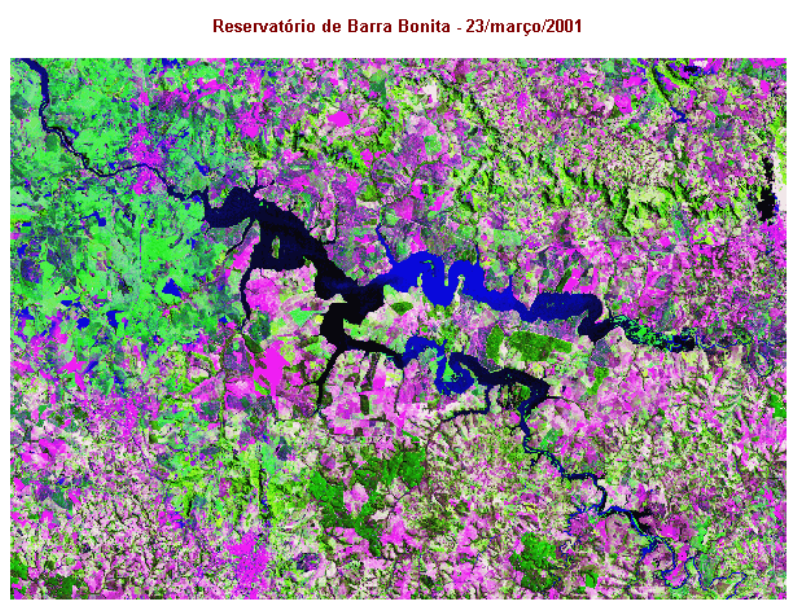

(a)

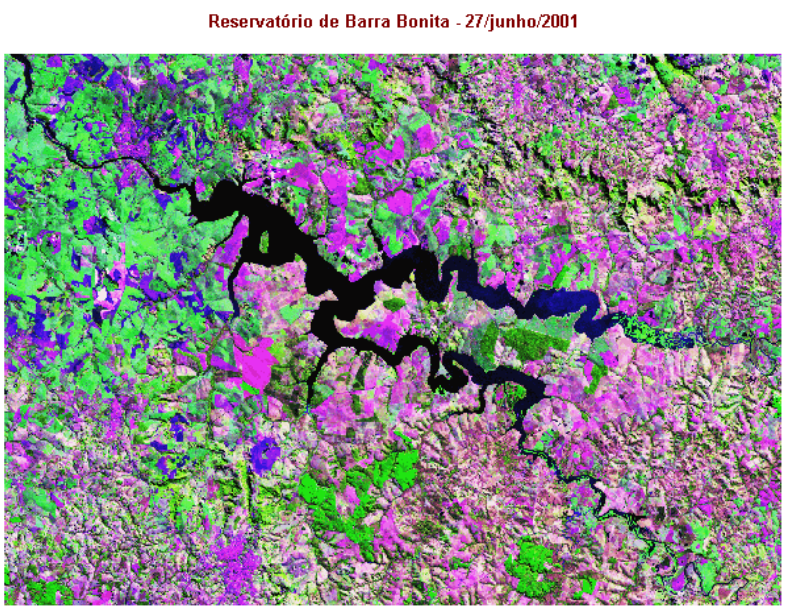

(b)

Figura 1 - Composições coloridas das bandas ETM+3, ETM+4 e ETM+5, associadas às cores azul (B), verde (G) e vermelho (R), respectivamente, representando o reservatório de Barra Bonita em: (a) março/2001 e (b) junho/2001.

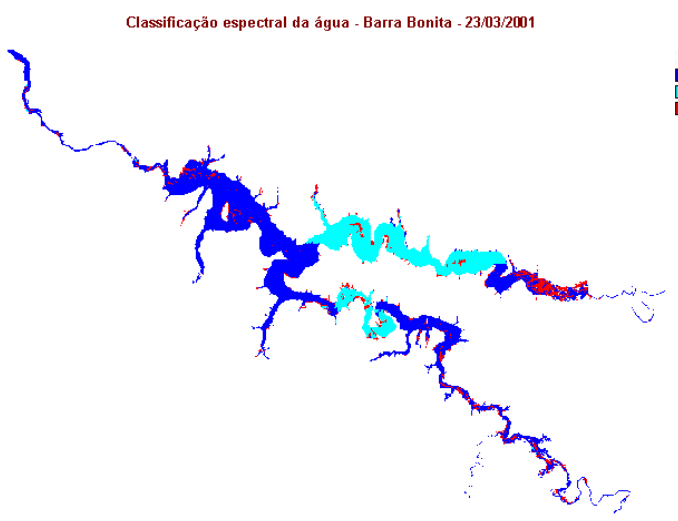

(a)

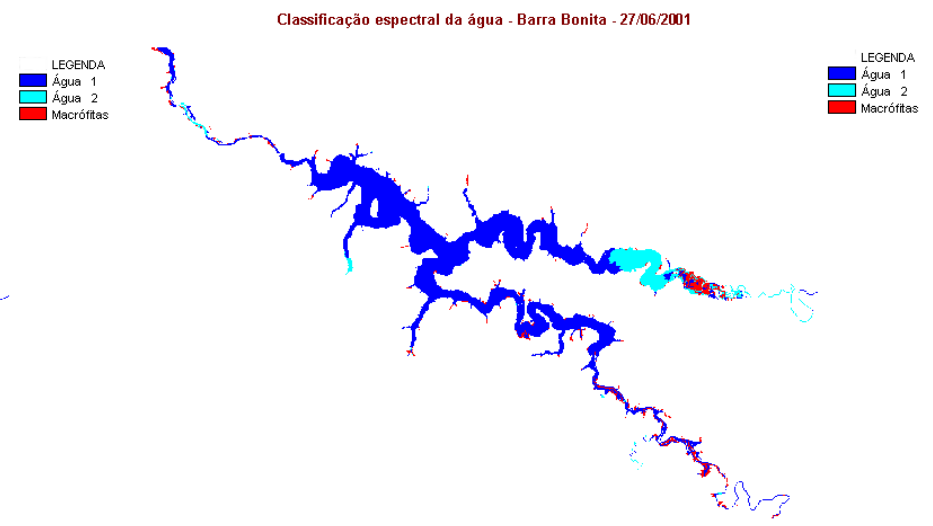

(b)

Figura 2 - Imagens resultantes da classificação espectral da água, representando o reservatório de Barra Bonita em: (a) março/2001 e (b) junho/2001.

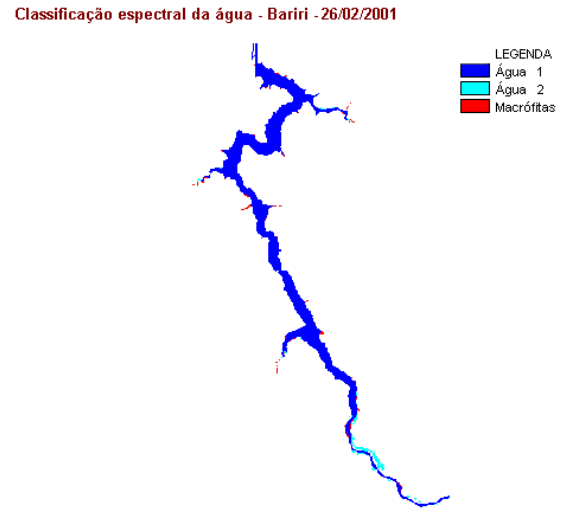

(a)

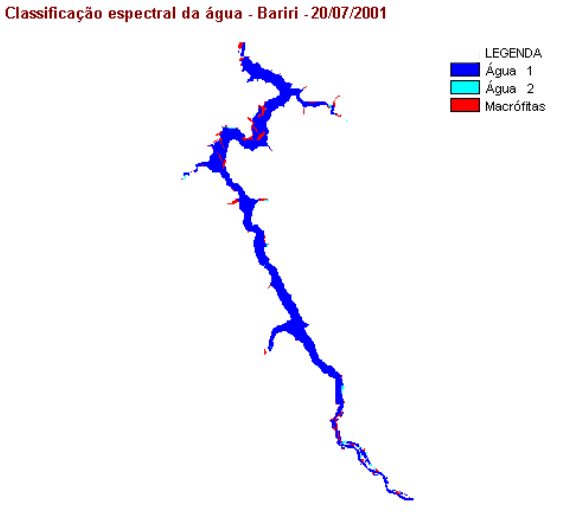

(b)

Figura 3 - Imagens resultantes da classificação espectral da água, representando o reservatório de Bariri em: (a) fevereiro/2001 e (b) julho/2001. 


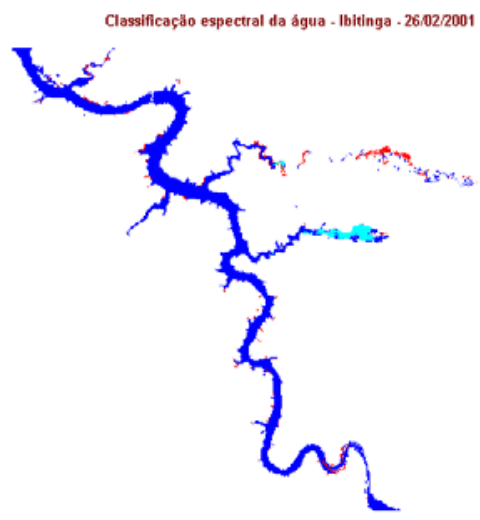

(a)

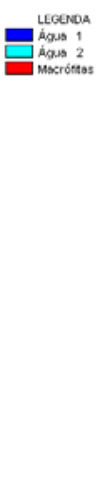

Figura 4 - Imagens resultantes da classificação espectral da água, representando o reservatório de Ibitinga em: (a) fevereiro/2001 e (b) julho/2001.

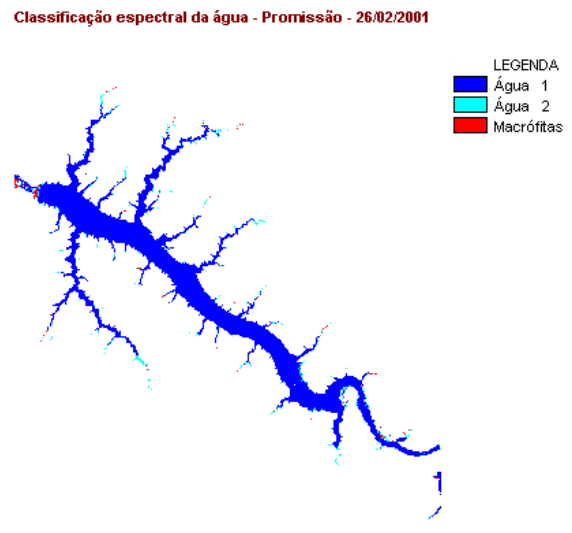

(a)

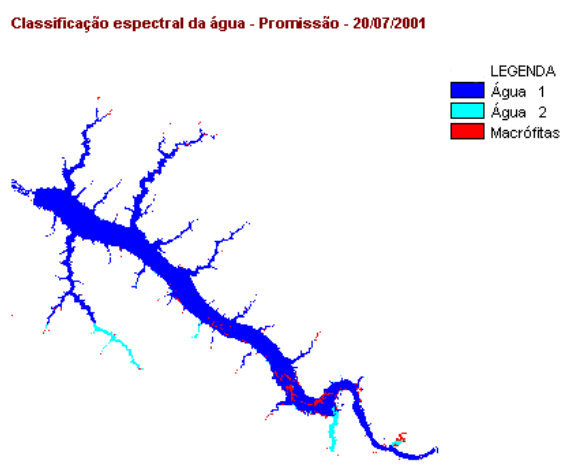

Figura 5 - Imagens resultantes da classificação espectral da água, representando o reservatório de Promissão em: (a) fevereiro/2001 e (b) julho/2001.

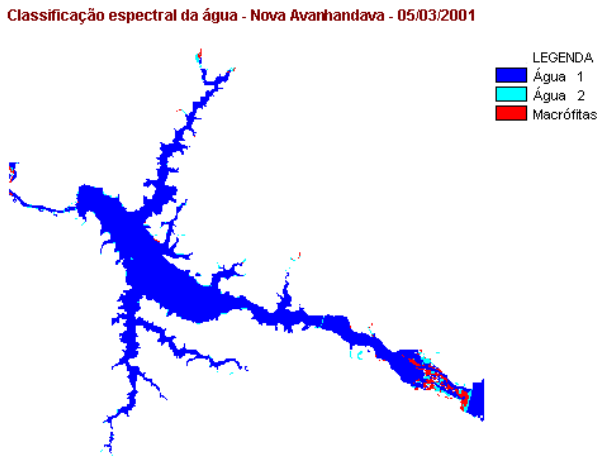

(a)

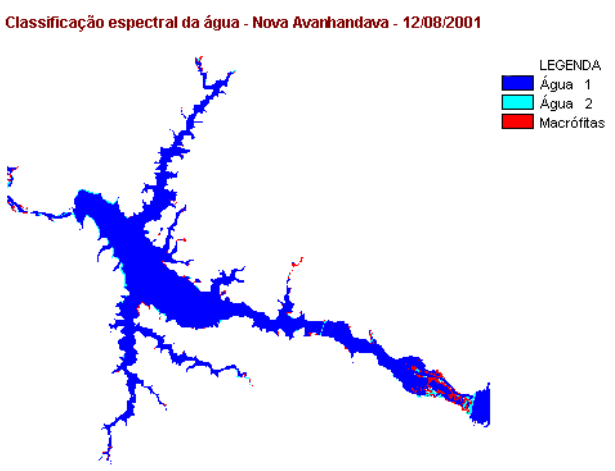

(b)

Figura 6 - Imagens resultantes da classificação espectral da água, representando o reservatório de Nova Avanhandava em: (a) fevereiro-março/2001 e (b) julho-agosto/2001. 
Na seqüência, as classificações obtidas para ambas as tomadas de imagem do reservatório de Nova Avanhandava (Figura 6) mostram que não há macrófitas emersas dispersas ao longo do espelho d'água, mas que a ocorrência dessas plantas está praticamente restrita à parte final do reservatório, próximo à Usina de Promissão. A mesma observação é válida quanto à presença de sedimentos em suspensão, modificando a coloração da água em Nova Avanhandava.

A fim de fornecer uma estimativa da área de ocorrência de macrófitas emersas e, eventualmente, das regiões onde houve detecção de variação na cor da água decorrente da presença de sedimentos (água 2), nos reservatórios da AES Tietê S.A., ao longo do rio Tietê, apresentase na Tabela 4 a área total estimada de reservatório, assim como de cada uma das classes mapeadas, diferenciados pela época de tomada dos dados multiespectrais: fevereiro-março/ 2001 (fase I) e junho-julho/2001 (fase II).

Através da Tabela 4 percebe-se que a superfície do espelho d'água reduziu consideravelmente na fase II (época mais seca) em relação à fase I (meses mais chuvosos), para os reservatórios de Barra Bonita, Ibitinga e Promissão. Os demais reservatórios, Bariri e Nova Avanhandava, exibem uma configuração oposta ao esperado, apontando acréscimo em área da época cheia para a seca. Cabe ressaltar que esses dois últimos reservatórios são do tipo filme líquido, enquanto Barra Bonita, Ibitinga e Promissão são reservatórios de acumulação.
Quanto à presença de macrófitas, observase pela Tabela 4 que apenas Barra Bonita acusou uma área consideravelmente maior dessa classe na fase I (época da cheia). Os demais reservatórios, sistematicamente, mostram aumento na área ocupada por macrófitas na fase II (seca).

Apesar das várias possibilidades de análise oferecidas pelas estimativas quantitativas da Tabela 4, é a representação espacial das áreas de infestação por macrófitas e das regiões de variação na cor da água decorrente da presença de sedimentos que fornece os elementos para avaliar a dispersão desses tipos de fenômenos e indica onde há necessidade de levantamentos e análises locais e de eventuais intervenções. No sentido de oferecer uma visão abrangente da dispersão espacial dessas ocorrências ao longo dos reservatórios que compõem o complexo Tietê, gerenciados pela AES Tietê S.A., as Figuras 7 e 8 mostram os mapeamentos temáticos resultantes da composição das classificações individuais dos cinco reservatórios, respectivamente para cada época de tomada de dados.

Além de indicar espacialmente as regiões caracterizadas pela ocorrência de macrófitas emersas e de concentração de sedimentos, a comparação entre as Figuras 7 e 8 indica a dinâmica desses fenômenos. Assim, enquanto na época da cheia - fase I (Figura 7) os bancos de macrófitas estavam praticamente restritos ao corpo d'água representado pelo reservatório de Barra Bonita, o período mais seco - fase II (Figura 8) se caracteriza pela dispersão dos bancos de macrófitas ao longo dos demais

Tabela 4 - Área total por reservatório e por classe (ha) estimada a partir da classificação desenvolvida no Spring, discriminando cada fase da análise

\begin{tabular}{|c|c|c|c|c|c|}
\hline \multirow{2}{*}{\multicolumn{2}{|c|}{ Reservatório }} & \multirow{3}{*}{$\begin{array}{c}\begin{array}{c}\text { Área estimada } \\
\text { (ha) }\end{array} \\
29.605\end{array}$} & \multicolumn{3}{|c|}{ Área estimada por classe (ha) } \\
\hline & & & \multirow{2}{*}{$\frac{\text { Água } 1}{18.562}$} & \multirow{2}{*}{$\frac{\text { Água } 2}{8.034}$} & \multirow{2}{*}{$\frac{\text { Macróftas }}{3.008}$} \\
\hline Borra Bonita & Fase I & & & & \\
\hline Danla Domila & Fase II & 27.718 & 22.907 & 2.940 & 1.871 \\
\hline \multirow{2}{*}{ Bariri } & Fase I & 5.282 & 4.904 & 233 & 145 \\
\hline & Fase II & 5.318 & 4.821 & 71 & 426 \\
\hline \multirow{2}{*}{ Ibitinga } & Fase I & 14.072 & 12.554 & 643 & 874 \\
\hline & Fase II & 12.716 & 10.167 & 903 & 1.645 \\
\hline \multirow{2}{*}{ Promissão } & Fase I & 58.774 & 54.659 & 3.189 & 925 \\
\hline & Fase II & 53.037 & 48.475 & 2390 & 2.172 \\
\hline \multirow{2}{*}{ Nova Avanhandava } & Fase I & 21.897 & 20.893 & 530 & 474 \\
\hline & Fase II & 22.545 & 21.180 & 558 & 806 \\
\hline
\end{tabular}




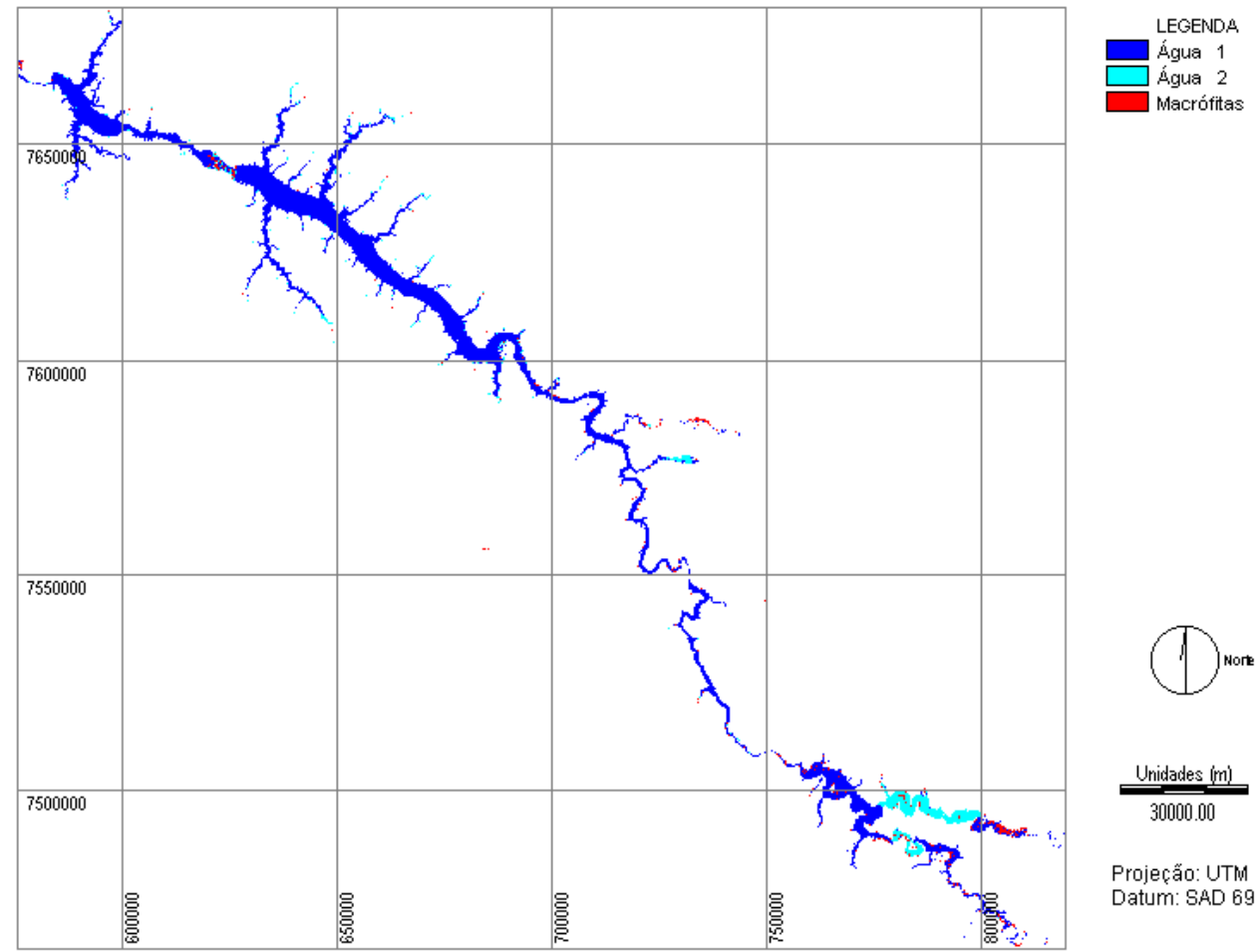

Figura 7 - Mapeamento temático resultante da composição das classificações individuais dos reservatórios do Complexo Tietê - fase 1, com base nas imagens ETM+/Landsat de fevereiro-março/2001.

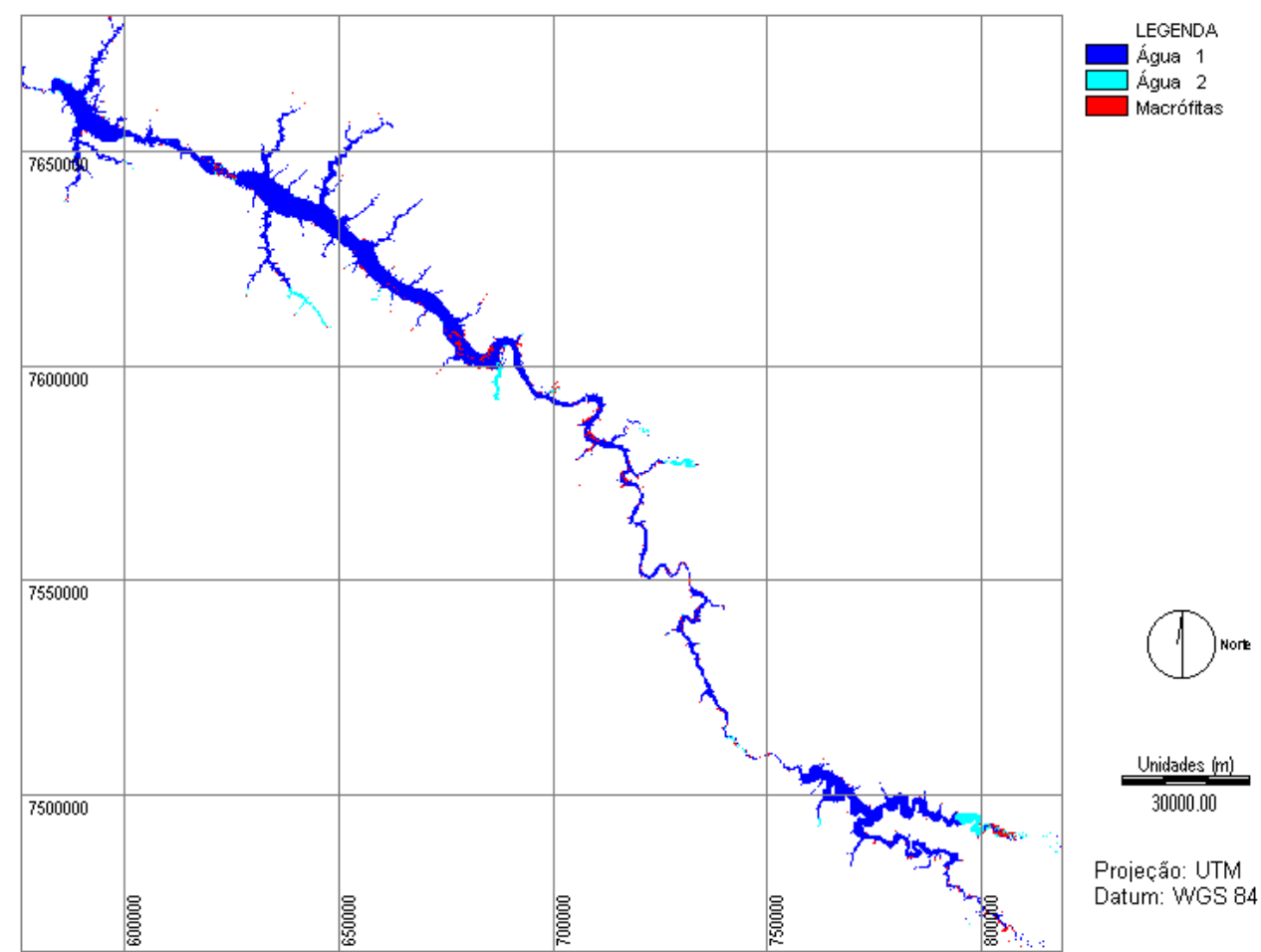

Figura 8 - Mapeamento temático resultante da composição das classificações individuais dos reservatórios do Complexo Tietê - fase 2, com base nas imagens ETM+/Landsat de junho-julho-agosto/2001. 
reservatórios. Aparentemente, os bancos de macrófitas, antes concentrados praticamente apenas em Barra Bonita, se deslocaram para os outros reservatórios, se concentrando nas partes mais meândricas formadas ao longo do rio Tietê. A estimativa quantitativa desse deslocamento, sugerida na Tabela 4 pela comparação das áreas ocupadas por macrófitas em cada reservatório, para cada época considerada, parece confirmar essa possibilidade.

Finalmente, na Tabela 5 são apresentadas, para cada época, as estimativas de área mapeada por classe para os cinco reservatórios em conjunto. Os números mostrados indicam que a superfície do espelho d'água (incluindo água 1 e água 2 - com cor diferenciada) teve uma considerável redução em área da época da cheia (fase I) para a época mais seca (fase II), o que faz sentido. Por outro lado, a área total ocupada por macrófitas ao longo dos cinco reservatórios avaliados aumentou na época mais seca.

Tendo em vista os resultados apresentados, pode-se considerar que as imagens orbitais de sensoriamento remoto constituem uma fonte de dados auxiliar particularmente útil para representar espacialmente e fornecer subsídios para uma análise abrangente da configuração de grandes reservatórios. Especificamente, a abordagem adotada permitiu avaliar a superfície ocupada pelo espelho d'água, além de estimar a área e a dispersão espacial de bancos de macrófitas emersas e de regiões de água turva pela presença de sedimentos em suspensão, de cinco reservatórios do rio Tietê, em duas épocas distintas de tomada de imagens.

As limitações quanto ao uso das imagens sistematicamente obtidas por sensores orbitais de sensoriamento remotas, relatadas por diversos autores e observadas no decorrer deste trabalho, estão relacionadas menos com a resolução espacial dos sistemas atualmente em operação, mas principalmente com a resolução

Tabela 5 - Estimativa de área por classe mapeada ao longo dos reservatórios do Complexo Tietê, gerenciados pela AES Tietê S.A.

\begin{tabular}{|c|c|c|c|}
\hline \multirow{2}{*}{ Fase } & \multicolumn{4}{|c|}{ Área estimada por classe (ha) } \\
\cline { 2 - 4 } & Água 1 & Água 2 & Macrófitas \\
\hline I (fev-mar) & 107.113 & 12.483 & 5.290 \\
II (jun-ago) & 103.651 & 6.568 & 6.800 \\
\hline
\end{tabular}

espectral das imagens adquiridas. A definição das bandas espectrais desses sistemas sensores não é especificamente adequada para registrar variações na resposta espectral da água, nem elas foram projetadas com essa finalidade.

Por se tratar de uma abordagem realizada em apenas duas etapas, o procedimento metodológico adotado mostrou-se adequado para definir espacialmente os pontos de amostragem para coleta de água ao longo dos reservatórios e para caracterizar, ainda que de modo abrangente, a ocorrência de macrófitas emersas e as regiões de água com cor diferente.

\section{LITERATURA CITADA}

CURRAN, P. J. Principles of remote sensing. London: Longman, 1985. 282 p.

INTERSAT. Ikomos. Disponível em : http:// www.intersat.com.br/ikonos. (06 Jul. 2001).

MOREIRA, M. A. Fundamentos do sensoriamento remoto e metodologias de aplicação. São José dos Campos: Instituto Nacional de Pesquisa Espacial, 2001. 205 p.

NOVO, E. M. L. M. Sensoriamento remoto: princípios e aplicações. São Paulo: Edgard Blücher, 1989. 308 p.

NOVO, E. M. L. M.; HAMSOM, J. D.; CURRAN, P. J. The effect of sediment type on the relationship between reflectance and suspended sediment concentration. Inter. J. Remote Sens., v. 10, n. 7, p. 1283-1289. 1989.

NOVO, E. M. L. M.; BRAGA, C. Z. F.; TUNDISI, J. G. Use of TM/Landsat data to retrieve the optically active water constituents from an eutrophic tropical reservoir. In: SIMPOSIUM RESOURCE AND ENVIRONMENTAL MONITORING, 1, 1994, Rio de Janeiro. Proceedings... Rio de Janeiro: Instituto de Pesquisa Espacial, 1994. p. 258-262.

ROBIN, M. La télédétection. Paris: Coll. Fac Géographie. 1995. $318 \mathrm{p}$.

RITCHIE, J. C.; SCHIEBE, F. R.; MCHENRY, J. R. Remote sensing of suspended sediments in surface waters. Photogr. Eng. Remote Sens., v. 42, p. 1540-1545, 1976.

SCARPACE, F. L.; HOLMQUST, K. W.; FISH!ER, L. T. Landsat analysis of lake quality. Photogr. Eng. Remote Sens., v. 45, n.5, p. 623-633, 1979.

SHEFFNER, E. Landsat 7. http://geo.arc.nasa.gov/sge/ landsat/17.html (05 Jun. 1999). 